\title{
Atorvastatin associated with decreased hazard for death in COVID-19 patients admitted to an ICU: a retrospective cohort study
}

\author{
Guillermo Rodriguez-Nava ${ }^{1 *}$ D, Daniela Patricia Trelles-Garcia', Maria Adriana Yanez-Bello ${ }^{1}$, Chul Won Chung ${ }^{1}$, \\ Valeria Patricia Trelles-Garcia² and Harvey J. Friedman ${ }^{3,4}$
}

Keywords: COVID-19, Emerging disease, Adjuvant therapies, Critical care, Atorvastatin, Statins, Immunomodulators

To the editor,

Since the World Health Organization (WHO) declared the coronavirus disease 2019 (COVID-19) a pandemic, the medical community started a race against time to find effective treatments for this disease [1]. Atorvastatin as adjuvant immunomodulatory therapy is of particular interest given its low cost, known safety profile, and availability. The severe acute respiratory syndrome coronavirus (SARS-CoV) has been shown to interact with Toll-like receptors on the host cell membrane, increasing the expression of the MYD88 gene, ultimately activating NF- $\mathrm{kB}$ and triggering inflammatory pathways. Experimental models have demonstrated that statins stabilize MYD88 levels after a pro-inflammatory trigger, and, in a murine model, atorvastatin significantly attenuated NF- $\kappa B$ activation [2]. Furthermore, in the real world, two retrospective cohort studies reported a reduced risk of influenza death among statin users [3, 4]. Therefore, we assessed whether statin users at a dose of $40 \mathrm{mg}$ daily had reduced inpatient mortality hazard from COVID-19.

In this retrospective cohort study, we used a deidentified dataset that included 87 adult patients with laboratory-confirmed COVID-19 admitted to our

\footnotetext{
* Correspondence: Guillermo.RodriguezNava@amitahealth.org

'Department of Internal Medicine, AMITA Health Saint Francis Hospital, Evanston IL, 355 Ridge Ave, Evanston 60202, IL, USA

Full list of author information is available at the end of the article
}

community hospital intensive care unit (ICU) located in Evanston, IL, from March to May 2020. We performed a Cox proportional hazards $(\mathrm{PH})$ regression model to examine the relationship between adjuvant treatments and inpatient mortality. To minimize confounders, we adjusted for age, hypertension, cardiovascular disease, invasive mechanical ventilation, severity according to the National Institutes of Health criteria (respiratory rate $>$ $30, \mathrm{SpO} 2<94 \%, \mathrm{PaO} 2 / \mathrm{FiO} 2<300 \mathrm{mmHg}$ or lung infiltrates $>50 \%$ ), number of comorbidities (as a continuous variable), and other adjuvant therapies (including hydroxychloroquine, intravenous steroids, azithromycin, tocilizumab, colchicine, and antibiotics), forcing these variables into the model. We also performed a sensitivity analysis calculating the $E$ value (with the lower confidence limit) as described by VanderWeele et al. $[5,6]$ for the obtained point estimate. The $E$ value is defined as the minimum strength of association on the risk ratio scale that an unmeasured confounder would need to have with both the exposure and the outcome, conditional on the measured covariates, to explain away a specific exposure-outcome association fully.

The median age was 68 years (interquartile range [IQR], $58-75$ years), 56 (64.4\%) were males, and 50 (57.5\%) were skilled nursing facility residents. Of these patients, 39 (44.8\%) were ultimately discharged from the hospital, median length of stay 13 days (IQR, 7 to 21 days), and 48 (55.2\%) had died, median length of stay 9.5 days (IQR, 
Table 1 Multivariable Cox regression of target interventions for COVID-19

\begin{tabular}{llll}
\hline Intervention & ${\text { Adjusted } \mathbf{H R}^{\mathbf{a}}}$ & $\mathbf{9 5 \%} \mathbf{C l}$ & $\boldsymbol{p}$ value $^{\mathbf{b}}$ \\
\hline Atorvastatin & 0.38 & $0.18-0.77$ & 0.008 \\
Steroids & 1.93 & $0.81-4.59$ & 0.136 \\
Hydroxychloroquine & 0.81 & $0.31-2.10$ & 0.675 \\
Colchicine & 0.41 & $0.17-0.98$ & 0.045 \\
Tocilizumab & 1.17 & $0.42-3.25$ & 0.765 \\
Azithromycin & 0.49 & $0.20-1.23$ & 0.132
\end{tabular}

Abbreviations: Cl confidence interval, COVID-19 coronavirus disease 2019, HR hazard ratio

${ }^{a}$ Adjusted for age, number of comorbidities, hypertension, cardiovascular disease, severity, invasive mechanical ventilation, and antibiotics other than azithromycin

${ }^{\mathrm{b}} p<0.05$ was considered statistically significant

3 to 14.75 days), a statistically significant difference ( $p=0.032$ by Mann-Whitney $U$ test). A total of 24 (61.5\%) survivors received atorvastatin $40 \mathrm{mg}$ daily compared to 23 (47.9\%) of non-survivors ( $p=0.20$ by chi-squared). In the multivariable $\mathrm{Cox} \mathrm{PH}$ regression model, atorvastatin non-users had a $73 \%$ chance of faster progression to death compared with atorvastatin users (when probability $=H R / H R+1)($ Table 1$)$. The $E$ value for the point estimate was 3.29 and the $E$ value for the lower confidence interval was 1.69 , meaning that a confounder not included in the multivariable Cox PH regression model associated with atorvastatin use and inpatient mortality in patients with COVID-19 by a hazard ratio of 1.69-fold each could explain away the lower confidence limit, but weaker confounding could not.

In conclusion, we found a slower progression to death associated with atorvastatin in patients with COVID19 admitted to our ICU. Given the observational nature of this study, results should be taken with caution; randomized controlled trials are needed to confirm this benefit (STATCO19, identifier NCT04380402). To date, supportive care remains the mainstay of therapy, and the clinical efficacy for various treatments is still under investigation.

\footnotetext{
Abbreviations

Cl: Confidence interval; COVID-19: Coronavirus disease 2019; HR: Hazard ratio ICU: Intensive care unit; IQR: Interquartile range; $\mathrm{PaO} 2 / \mathrm{FiO} 2$ : Arterial oxygen partial pressure to fractional inspired oxygen; $\mathrm{PH}$ : Proportional hazards; SARS-CoV: Severe acute respiratory syndrome coronavirus; SpO2: Oxygen saturation; WHO: World Health Organization
}

\section{Acknowledgements}

We dedicate this work to the intensive care unit nurses who did a fantastic job during the peak of the crisis, taking care of a higher patient ratio than usual, providing compassionate and high-quality care regardless of the increased workload, and risking their health selflessly to help the community. Without them, our work would have been harder.

\section{Authors' contributions}

GRN: conceptualization, acquisition of the dataset, statistical analysis, original draft preparation, reviewing, literature review, and editing. DPTG: conceptualization, writing, and reviewing. MAYB, CWC, and VPTG: manuscript revision. HJF: study supervisor. All the authors read and approved the manuscript.

\section{Funding}

This research did not receive any specific grant from funding agencies in the public, commercial, or not-for-profit sectors.

\section{Availability of data and materials}

The datasets used and analyzed during the current study are available from the corresponding author on reasonable request.

\section{Ethics approval and consent to participate}

Research using de-identified data does not constitute research with human subjects because there is no interaction with any individual, and no identifiable private information is used. The project did not, therefore, require IRB or ethics committee review by AMITA Health.

\section{Consent for publication}

The research presents no more than minimal risk of harm to subjects and involves no procedures; hence, written consent requirement was waived.

\section{Competing interests}

The authors declare no conflict of interest.

\section{Author details}

'Department of Internal Medicine, AMITA Health Saint Francis Hospital, Evanston IL, 355 Ridge Ave, Evanston 60202, IL, USA. ${ }^{2}$ Department of Internal Medicine, John H. Stroger Jr. Hospital of Cook County, Chicago, IL, USA. ${ }^{3}$ Critical Care Units, AMITA Health Saint Francis Hospital, Evanston, IL, USA.

${ }^{4}$ University of Illinois College of Medicine, Chicago, IL, USA.

Received: 19 June 2020 Accepted: 5 July 2020

Published online: 14 July 2020

\section{References}

1. Mccreary EK, Pogue JM. Coronavirus disease 2019 treatment: a review of early and emerging options. Open Forum Infect Dis. 2020;7(4):ofaa105.

2. Castiglione V, Chiriacò M, Emdin M, Taddei S, Vergaro G. Statin therapy in COVID19 infection. Eur Heart J Cardiovasc Pharmacother. 2020. [Epub ahead of print].

3. Frost FJ, Petersen H, Tollestrup K, Skipper B. Influenza and COPD mortality protection as pleiotropic, dose-dependent effects of statins. Chest. 2007; 131(4):1006-12.

4. Vandermeer ML, Thomas AR, Kamimoto L, et al. Association between use of statins and mortality among patients hospitalized with laboratory-confirmed influenza virus infections: a multistate study. J Infect Dis. 2012;205(1):13-9.

5. VanderWeele TJ, Ding P. Sensitivity analysis in observational research: introducing the E-value. Ann Intern Med. 2017;167(4):268-74.

6. Mathur MB, Ding P, Riddell CA, VanderWeele TJ. Website and R package for computing E-values. Epidemiology. 2018;29(5):e45-7.

\section{Publisher's Note}

Springer Nature remains neutral with regard to jurisdictional claims in published maps and institutional affiliations.
Ready to submit your research? Choose BMC and benefit from:
- fast, convenient online submission
- thorough peer review by experienced researchers in your field
- rapid publication on acceptance
- support for research data, including large and complex data types
- gold Open Access which fosters wider collaboration and increased citations
- maximum visibility for your research: over $100 \mathrm{M}$ website views per year
At BMC, research is always in progress.
Learn more biomedcentral.com/submissions 